\title{
EFFECT OF AEROBIC EXERCISES AND RESISTANCE TRAINING ON GLUCOSE LEVELS IN TYPE 2 DIABETIC SUBJECTS
}

\author{
AISHWARYA PRAMOD BENKAR, SMITA BHIMRAO KANASE* \\ Department of Musculoskeletal Sciences, Krishna Institute of Medical Sciences Deemed University, Faculty of Physiotherapy, \\ Karad - 415 110, Satara, Maharashtra, India. Email: smitakanase@gmail.com
}

Received: 17 March 2017, Revised and Accepted: 19 April 2017

\section{ABSTRACT}

Objective: Diabetes mellitus is a leading cause of death and disability in the world and its prevalence is predicted to rise to $10 \%$ by 2030 . Hence, this study is conducted with objectives to find out the effect of aerobic exercises and resisted exercises on blood glucose levels in type 2 diabetes mellitus (T2DM) subjects and to compare the effect of both exercises on blood glucose level.

Method: The comparative study was conducted at Krishna Institute of Medical Sciences Deemed University, Physiotherapy department, Karad. 30 participants with age group between 30 and 65 years were taken. Subjects were selected as per inclusion and exclusion criteria. Group A (15) participants were given aerobic exercise on static bicycle, and Group B (15) participants were given resistance training using dumbbells and weight cuffs for 5 days/week for 4 weeks. Diet recommendations were given to every participant.

Results: Statistical analysis was performed using paired and unpaired t-test. Analysis showed statistically extremely significant difference in fasting blood glucose level and postprandial blood glucose level in both the groups $(\mathrm{p} \leq 0.0001)$.

Conclusion: Thus, this study concludes that both aerobic exercises and resistance training prove to be beneficial in controlling blood glucose levels in T2DM subjects.

Keywords: Type 2 diabetes, Aerobic exercises, Resistance training, Blood glucose levels.

(C) 2017 The Authors. Published by Innovare Academic Sciences Pvt Ltd. This is an open access article under the CC BY license (http://creativecommons. org/licenses/by/4. 0/) DOI: http://dx.doi.org/10.22159/ajpcr.2017.v10i7.18532

\section{INTRODUCTION}

The etiology of diabetes in India is multifactorial and includes genetic factors coupled with environmental influences such as obesity associated with rising living standards, steady urban migration, and lifestyle changes [1].

Diabetes is a group of metabolic diseases characterized by hyperglycemia resulting from defects in insulin secretion, insulin action, or both. It develops many secondary complications and is making it the $5^{\text {th }}$ leading causes of death in human [2]. In type 1 diabetes, the cause is deficiency of insulin secretion. In type 2 diabetes, the cause is a combination of resistance to insulin action and an inadequate compensatory insulin secretory response. In type 2 diabetes, a degree of hyperglycemia sufficient to cause pathologic and functional changes in various target tissues, but without clinical symptoms, may be present for a long period before diabetes is detected. Among all the diabetic subjects $90-95 \%$ are suffering from type 2 diabetes $[3,4]$.

Diet and physical exercise are important in the management and prevention of type 2 diabetes because they help in treating the associated glucose, lipid, blood glucose control abnormalities, as well as help in weight loss and maintenance. Along with proper medications, the lifestyle modification is equally important. Any increase in muscle mass that may result from resistance training could contribute to blood glucose uptake without altering the muscle's intrinsic capacity to respond to insulin, whereas aerobic exercise enhances its uptake via a greater insulin action, independent of changes in muscle mass or aerobic capacity [5].

Aerobic exercises are rhythmic, repeated and continuous movements of same large muscle groups for at least 10 minutes. The intensity of aerobic exercises for type 2 diabetes is described as moderate when it is at $40-60 \%$ of $\mathrm{VO}_{2} \max (50-70 \%$ of maximum heart rate) and vigorous when it is at $>60 \%$ of $\mathrm{VO}_{2} \max (>70 \%$ of maximum heart rate). Various forms include walking, cycling, jogging, and swimming.

Resisted exercises are those which use muscle strength to move weight or work against a resistive load. The resistance training should be performed on at least 2 days per week, with a minimum of 8-10 exercises involving the major muscle groups for 10-15 repetitions to near fatigue. The resistance training be included as an essential component of a wellbalanced physical activity program for those with type 2 diabetes who do not have contraindications to exercise $[6,7]$.

Up to the present, no researches have been conducted on the basis on low-intensity exercises in the age group of 30-60 years of age. Many researches are been conducted finding the effect of high graded exercises and comparison of both aerobic and resistance exercises with any one of the exercises method. However, this study is first of its kind focusing on the effect of low-intensity exercises along with warm up and cool down exercises. Moreover, this study also concentrates on diet, heart rate, and pulse rate during ongoing of exercises. The findings may also differ from person to person and country to country. Today's world is the world of unhealthy diet and improper lifestyle. With the increasing tendency of health awareness, it is the need to find out whether the exercises can prove to be harmful or beneficial in medical conditions like diabetes mellitus. Having an idea about the effect of exercises such as aerobic exercises and resistance training, it will be important in controlling and maintaining blood glucose levels which may lead in healthy lifestyle of individuals suffering from type 2 diabetes mellitus (T2DM). Findings of this study will help in prescribing proper exercise plan for individuals with diabetes mellitus. 


\section{METHODS}

Ethical approval for the study was granted by the Institutional Ethical Committee of Krishna Institute of Medical Sciences, Karad. An experimental study was conducted to assess the effect of aerobic exercises and resistance training on blood glucose levels in type 2 diabetes subject. The participants who meet the inclusion and exclusion criteria and willing to participate in the study were included in the study. We had approached and assessed 30 individuals as our study population. The participants were explained about the study and the evaluation procedure. Both males and female subjects willing to participate in the study with the age group between 30 and 65 years, who were diagnosed with T2DM for more than 4 years were included in the study. The exclusion criterion of the study was (1) patients on current insulin therapy. (2) Severe retinopathy, neuropathy, nephropathy. (3) History of serious cerebrovascular or cardiovascular diseases. (4) Severe musculoskeletal problems restricting physical activity. (5) Participation in exercise 2 or more times weekly for 20 minutes or longer per session.

The study design was pre- and post-experimental design with convenient sampling method. The participants were divided into two: Groups A and B.

\section{Procedure}

A written consent was taken from each subject, and they were screened as per inclusion and exclusion criteria. Before starting the treatment, the blood glucose levels both fasting as well as postprandial of every subject were noted along with vitals (blood pressure and pulse rate).

\section{Exercise protocol}

Group A participants were treated with aerobic exercises, and Group B participants were treated with resisted exercise training. The treatment was given for 5 days per week for consecutive 4 weeks for both groups. Each day session lasted for 30 minutes with 10 minutes warm up and 5 minutes cool down phase for both groups and 15 minutes of actual training with either aerobic exercise or resistance training as per the group to which the participant was selected for.

\section{Warm up phase}

Participants performed 10 minutes of warm up which included selfstretching of major muscles of upper and lower body. The exercises included stretch to pectoralis major, deltoid, shoulder capsular stretch, calf stretch, tibialis anterior stretch, hamstring, and quadriceps stretch. Each stretch was maintained for 10 seconds in 2 sets.

\section{Aerobic training}

The participants from Group A were asked to commence the session by self-stretching of all muscle groups for 10 minutes followed by static bicycling for 15 minutes and cool down for 5 minutes by self-stretching.

\section{Resistance training}

The exercises which were given to the study Group B are self stretching as warm up for 10 minutes followed by resisted training that includes dumb bell exercises for upper limb and weight cuffs for lower limb bilaterally with 8 repetitions each, for 15 minutes and at the end 5 minutes cool down by self-stretching. The exercises were performed with the close supervision of the physiotherapist. 1 repetition maximum (1 RM) for each exercise was calculated as maximum amount of weight that was lifted for one repetition. The weight for each exercise was calculated as per $1 \mathrm{RM}$.

The chances of hypoglycemic episodes during the sessions were monitored, and blood pressure fluctuation was assessed regularly. The subjects were asked to have sweet eatable or drinkable things and not to use their lunches or medications just before the beginning of training. Water was supplied as required by their bodies in the middle of sessions. All the exercise training was done according to American
College of Sports Medicine guidelines. Every participant was asked to perform the decided form of exercises within $60-70 \%$ of maximum heart rate. The target heart rate to be maintained during exercise by both the groups were decided on the basis of Karvonen's formula. Proper rest intervals were given to the participants during the session.

Main outcome measures:

1. Fasting blood glucose level

2. Postprandial blood glucose level.

The outcome measures were taken preintervention on the $1^{\text {st }}$ day of assessment and postintervention after 4 weeks of intervention.

\section{Statistical analysis}

Statistical analysis was performed manually as well as using the statistics software INSTAT so as to verify the results obtained. Various statistical measures such as mean, standard deviation, and paired and unpaired test of significance were utilized for this purpose. $\mathrm{p}<0.05$ was considered statistically significant and $\mathrm{p}<0.0001$ were considered statistically extremely significant.

\section{RESULTS}

\section{Demographic data}

Age group of all participants is between 30 to 65 years. The mean age of the participants in Group A was 53.86 years and in Group B was 54 years. There was no significant difference between the mean ages of the participants in both the groups. This was done using unpaired t-test $(\mathrm{t}=0.04203$ and $\mathrm{p}=0.9671)$ (Table 1$)$.

Both the groups included male and female participants. Among 30 participants, 14 were male participants which contribute to $47 \%$ of total sample size and 16 were female participants which contribute remaining $53 \%$ of total sample size (Table 2 ).

\section{Outcome measure comparison}

\section{Fasting blood glucose level}

The preinterventional fasting blood glucose level was 144.06 in Group A and 142.84 in Group B, respectively, whereas postintervention fasting blood glucose level was 139.65 in Group A and 139.82 in Group B. Within group changes in fasting blood glucose level reveals statistically extremely significant difference and reduction in fasting blood glucose level for both groups ( $\mathrm{p} \leq 0.0001, \mathrm{t}=10.83$ for Group A and $\mathrm{p} \leq 0.0001, \mathrm{t}=7.042$ for Group B). This was done using paired t-test. The between group analysis for pre- and post-intervention values of fasting blood glucose levels showed no significant difference for both the groups ( $\mathrm{p}=0.9117, \mathrm{p}=0.9880$ ). This was done using unpaired $\mathrm{t}$-test. This shows that both aerobic exercises and resistance training were equally effective in reducing the fasting blood glucose levels in both the groups (Table 3).

\section{Postprandial blood glucose level}

The preinterventional postprandial blood glucose level was 192.46 in Group A and 191.66 in Group B, respectively, whereas postintervention

Table 1: Age distribution in Groups A and B

\begin{tabular}{lllllll}
\hline \multirow{2}{*}{ Parameter } & Mean \pm SD & & p value & t value & Significance \\
\cline { 2 - 5 } & Group A & Group B & & & \\
\hline Age & $53.86 \pm 9.23$ & $54 \pm 7.75$ & 0.9671 & 0.04203 & NS \\
\hline
\end{tabular}

NS: Not significant, SD: Standard deviation

Table 2: Total participants in the study

\begin{tabular}{ll}
\hline Gender & Participants (\%) \\
\hline Male & $14(47)$ \\
Female & $16(53)$ \\
\hline
\end{tabular}


fasting blood glucose level was 181.42 in Group A and 189.30 in Group B. Within group changes in postprandial blood glucose level reveals statistically extremely significant difference and reduction in fasting blood glucose level for both groups ( $p \leq 0.0001$ and $t=6.951$ for Group $A$ and $p<0.0001$ and $t=7.788$ for Group B). This was done using paired $\mathrm{t}$-test. The between group analysis showed, there was no significant difference between pre- and post-intervention values of postprandial blood glucose level for both the groups ( $p=0.9469, p=0.5277$ ). This was done using unpaired $t$-test. This shows that both aerobic exercises and resistance training were equally effective in reducing the postprandial blood glucose levels in both the groups (Table 4).

\section{DISCUSSION}

T2DM is one of the leading causes of morbidity and mortality for $90-95 \%$ of all diabetic cases [8].

Despite effective drug therapies and advanced clinical diagnostic methods, the incidence of type 2 diabetes and insulin resistance have increased in last decades $[9,10]$.

This research was undertaken with the aim to study and compare the effect of aerobic exercise and resistance training in management of T2DM. 30 patients (14 male and 16 female) diagnosed as T2DM of age group 30 to 65 years approaching and referred to outpatient department of Krishna College of Physiotherapy, Karad participated in the study. They were divided into two groups by convenient sampling method. Each group had 15 patients thorough necessary required assessment was done before application of treatment strategy.

The participants from Group A were treated with 10 minutes of selfstretching as warm up followed by 15 minutes static bicycling and 5 minutes of cool down by self-stretching. The participants from Group B were treated with 10 minutes of self-stretching as warm up followed by 15 minutes resistance training and 5 minutes of cool down by self-stretching. Preintervention outcome measures for fasting blood glucose level, postprandial blood glucose level was done with glucometer. Postintervention assessment was done after 4 weeks of intervention.

Out of 30 participants, the gender distribution in this study included 16 females and 14 males. The mean age for Group A was 53.86 years and in Group B was 54 years. The subject was within the age group from 30 to 65 years. The prevalence rate is more in this age group.
Furthermore, several studies have shown more female dominance for diabetes [11]. The statistical analysis showed no significant difference between age distributions between both the groups.

The pre- and post-intervention comparison of fasting blood glucose values showed extremely significant difference within both the groups. The analysis was performed using paired $t$ test for within group comparison. This proves that both aerobic and resistance training was effective in reducing fasting blood glucose levels $(p<0.0001)$. The postprandial blood glucose level was also found to be reduced in both the groups on within group analysis. There was extremely significant difference between postprandial blood glucose values pre- and postintervention for both the groups $(\mathrm{p}<0.0001)$.

However, the between groups comparison showed statistically no significant difference between pre- and post-intervention values of fasting blood glucose level and postprandial blood glucose levels between both the groups. This indicates that both aerobic exercise and resistance training are equally effective in reducing the fasting and postprandial blood glucose level in both the groups.

A number of studies conducted so far on positive effects of exercise and physical activity on insulin sensitivity and glycemic control [12-14].

Aerobic exercises have long term, positive effects on glucose metabolism. This effect is thought to be related with the changes that occur in body composition including decrease in total and central lipid indexes $[15,16]$. A study conducted by Marino et al. has shown the positive influence of exercise on control of glycemic index. This study has noted decrease in peak oxygen intake, exercise test duration, HbA1c level, and fasting plasma glucose level [17].

Resistance training improves muscular strength and endurance, enhances flexibility and body composition, and decreases the risk of cardiovascular disease. Possible underlining mechanisms for positive effects of resistance (strength) training may be the increase in the number of glucose transporter (GLUT) proteins, increasing total muscle mass, and an increased number of insulin receptors in the muscle cell. Aerobic exercise modifies the insulin action of each fiber without increasing fiber size. Aerobic exercise is known to manage glycemic control and cardiovascular risk factors. It has also beneficial effects for metabolic profile in patients with T2DM. Aerobic (endurance) exercise increases skeletal muscle capitalization and

Table 3: Comparison of mean pre- and post-treatment fasting blood glucose level of Groups A and B

\begin{tabular}{lllll}
\hline Groups & Mean \pm SD & & p value & Significance \\
\cline { 2 - 3 } & Pre-treatment & Post-treatment & & \\
\hline Group A & $144.06 \pm 40.43$ & $139.65 \pm 0.68$ & $<0.0001$ & 10.83 \\
Group B & $142.84 \pm 12.88$ & $139.82 \pm 12.81$ & $<0.0001$ & \\
p value & 0.9117 & 0.9880 & & \\
t value & 0.1119 & 0.0151 & & \\
Significance & NS & NS & \\
DOF & 28 & 28 & \\
\hline
\end{tabular}

ES: Extremely significant, NS: Not significant, SD: Standard deviation

Table 4: Comparison of mean pre- and post-treatment postprandial blood glucose levels of Groups A and B

\begin{tabular}{lllll}
\hline Groups & \multicolumn{1}{l}{ Mean \pm SD } & p value & Significance \\
\cline { 2 - 3 } & Pre-treatment & Post-treatment & & \\
\hline Group A & $192.46 \pm 38.52$ & $181.42 \pm 40.26$ & $<0.0001$ & \\
Group B & $191.66 \pm 25.34$ & $189.30 \pm 25.61$ & $<.0001$ & \\
p value & 0.9469 & 0.5277 & & \\
t value & 0.0672 & 0.6395 & & \\
Significance & NS & NS & & \\
DOF & 28 & 28 & & \\
\hline
\end{tabular}

ES: Extremely significant, NS: Not significant, SD: Standard deviation 
blood flow, muscular GLUT4 levels, hexokinase, and glycogen synthase activities [18].

The studies also correlate the findings of study done by Kartono et al. who stated that physical exercise improved glucose control and enhanced insulin sensitivity in subjects with diabetes mellitus. The same was noticed in our study which helped in controlling the glucose levels [19].

Thus, in this study, both resistance training and aerobic exercises have been proved to be effective in controlling blood glucose levels as these exercises utilize body fat for performing the desired exercises which help in maximum use of glucose, resulting in controlling blood glucose levels.

\section{CONCLUSION}

Participants from both the groups showed statistically extremely significant improvement in fasting and postprandial blood glucose levels. Thus, both aerobic and resistance training have been proven to be beneficial in controlling blood glucose levels.

\section{REFERENCES}

1. Kaveseshwar SA, Corwall J. The current state of diabetes mellitus in India: US National library of medicine national institute of health. Australas Med J 2014;7(1):45-8.

2. Maanvizhi S, Boppana T, Krishnan C, Arumugan G. Metal complexes in the management of diabetes Mellitus: A new Therapeutic Strategy. Int J Pharm Pharm Sci 2014;6(7):40-4

3. Genuth S, Alberti KG, Bennett P, Buse J, Defronzo R, Kahn R. Expert committee on the diagnosis and classification of diabetes mellitus. Report of the expert committee on the diagnosis and classification of diabetes mellitus. Diabetes Care 1997;20:1183-97.

4. Genuth S, Alberti KG, Bennett P, Buse J, Defronzo R, Kahn R, et al. Follow-up report on the diagnosis of diabetes mellitus. Diabetes Care 2003;26(11):3160-7.

5. Colberg SR, Sigal RJ, Fernhall B, Regensteiner JG, Blissmer BJ, Rubin RR, et al. Exercise and Type 2 diabetes: The American College of Sports Medicine and the American Diabetes Association: Joint position statement. Diabetes Care 2010;33(12):e147-67.
6. Eves ND, Plotnikoff RC. Resistance training and type 2 diabetes: Considerations for implementation at the population level. Diabetes Care 2006;29(8):1933-41.

7. Marcus RL, Smith S, Morrell G, Addison O, Dibble LE, Wahoff-Stice D, et al. Comparison of combined aerobic and high-force eccentric resistance exercise with aerobic exercise only for people with type 2 diabetes mellitus. Phys Ther 2008;88(11):1345-54.

8. Albright A, Franz M, Hornsby G, Kriska A, Marrero D, Ullrich I, et al. American College of Sports Medicine position stand. exercise and Type 2 diabetes. Med Sci Sports Exerc 2000;32(7):1345-60.

9. Harris MI. Classification Diagnostic Criteria, and Screening for Diabetes. Diabetes in America Sponsored by National Data Group. Vol. 10. New Delhi: NIH, NIDDK Publication; 1995. p. 95-1468.

10. Peinado AB, Rojo-Tirado MA, Benito PJ. Sugar and exercise: Its importance in athletes. Nutr Hosp 2013;28 Suppl 4:48-56.

11. Sadikot SM, Nigam A, Das S, Bajaj S, Zargar AH, Prasannakumar KM. Diabetes India. The burden of diabetes and impaired fasting glucose in India using the ADA1997 criteria: Prevalence of diabetes in India study (PODIS). Diabetes Res Clin Pract 2004;66:293-300.

12. Koivisto VA, Defronzo RA. Exercise in the treatment of Type 2 diabetes. Acta Endocrinol 1984;2:107-11.

13. American Diabetes Association. Diabetes: 1996. Vital Statistics. Alexandria, VA; 1996. p. 11-74.

14. Burstein R, Epstein Y, Shapiro Y, Charuzi I, Karnieli E. Effect of an acute bout of exercise on glucose disposal in human obesity. J Appl Physiol 1990;69(1):299-304.

15. Dela F, Mikines KJ, Sonne B, Galbo H. Effect of training on interaction between insulin and exercise in human muscle. J Appl Physiol 1994;76(6):2386-93.

16. Farese RV. Function and dysfunction of aPKC isoforms for glucose transport in insulin-sensitive and insulin-resistant states. Am J Physiol Endocrinol Metab 2002;283(1):E1-11.

17. Maiorana A, O’Driscoll G, Goodman C, Taylor R, Green D. Combined aerobic and resistance exercise improves glycemic control and fitness in Type 2 diabetes. Diabetes Res Clin Pract 2002;56(2):115-23.

18. Cauza E, Hanusch-Enserer U, Strasser B, Ludvik B, Metz-Schimmerl S, Pacini G, et al. The relative benefits of endurance and strength training on the metabolic factors and muscle function of people with type 2 diabetes mellitus. Arch Phys Med Rehabil 2005;86(8):1527-33.

19. Kartono A, Irawati FD, Setiawan A, Syafutra H, Sumaryada T. Effects of physical exercise on the insulin dependent diabetes mellitus subjects using modified minimal model. Int $\mathrm{J}$ Pharm Pharm Sci 2017;9(2):179-86 